\title{
Limited-are a modelling of stratocumulus over South-Eastern Pacific
}

\author{
M. Andrejczuk ${ }^{1, *}$, W. W. Grabowski ${ }^{2}$, A. Gadian ${ }^{1}$, and R. Burton ${ }^{1}$ \\ ${ }^{1}$ School of Earth and Environment, University of Leeds, Leeds LS2 9JT, UK \\ ${ }^{2}$ National Center for Atmospheric Research, Boulder, Colorado, USA \\ *now at: Department of Physics, University of Oxford, Oxford OX1 3PU, UK
}

Correspondence to: M. Andrejczuk (m.andrejczuk1@physics.ox.ac.uk)

Received: 23 August 2011 - Published in Atmos. Chem. Phys. Discuss.: 12 September 2011

Revised: 10 February 2012 - Accepted: 22 March 2012 - Published: 11 April 2012

\begin{abstract}
This paper presents application of the Weather Research and Forecasting (WRF) model to limited-area modeling of atmospheric processes over the subtropical southeastern Pacific, with the emphasis on the stratocumulustopped boundary layer. The simulations cover a domain from the VAMOS (Variability of the American Monsoon Systems) Ocean-Cloud-Atmosphere-Land Study Regional Experiment (VOCALS-REx) field project conducted in the subtropical south-eastern Pacific in October and November 2008. We focus on a day where the UK's BAe-146 research aircraft encountered Pockets of Open Cells (POCs) at the very western edge of its flight track, rather than on the entire campaign as investigated in previous limited-area modeling studies. Model results are compared to aircraft observations with the main conclusion that the simulated stratocumulus-topped boundary layer is significantly too shallow. This appears to be a combination of an already too shallow boundary layer in the dataset used to provide initial and lateral boundary conditions, and the inability of the WRF model to increase the boundary-layer height. Several sensitivity simulations, applying different subgrid-scale parameterizations available in the model, a larger computational domain and longer simulations, as well as a different dataset providing initial and lateral boundary conditions were all tried to improve the simulation. These changes appeared to have a rather small effect on the results.
\end{abstract}

The model does simulate the formation of mesoscale cloud-free regions that one might consider similar to Pockets of Open Cells observed in nature. However, formation of these regions does not seem to be related to drizzle-induced transition from open- to closed-cell circulations as simulated by LES models. Instead, the cloud-free regions appear to result from mesoscale variations of the lower-tropspheric vertical velocity. Areas of negative vertical velocity with minima (a few $\mathrm{cm} \mathrm{s}^{-1}$ ) near the boundary layer top seem to induce direct evaporation of the cloud layer. It remains to be seen in LES studies whether the mechanism seen in the model is realistic or if it is simply an artifact of interactions between resolved and parameterized processes.

\section{Introduction}

Numerical models are the only tools that can be used to objectively predict evolution of the state of the atmosphere. However, due to limited spatial and temporal resolutions, these models require parametrizations of unresolved processes. As a result, the model solutions depend not only on the initial and boundary conditions as well as on spatial and temporal resolutions, but also on specific parametrizations applied in the simulations. This especially applies to limitedarea modeling because of the disparity between model horizontal gridlength (typically $\sim 10 \mathrm{~km}$ ) and gridlengths required to resolve boundary-layer processes, turbulent transports in particular.

The VAMOS (Variability of the American Monsoon Systems) Ocean-Cloud-Atmosphere-Land Study Regional Experiment (VOCALS-REx) field project conducted in the subtropical south-eastern Pacific in October and November 2008 (Wood et al., 2011b) provided copious data for model evaluation and validation. The atmospheric conditions in this region are determined by the large-scale free-tropospheric 
subsidence and low sea surface temperature (SST). Similarly to the subtropical region off the California coast, such conditions lead to a cold well-mixed boundary layer topped by a persistent stratocumulus deck (Rahn and Garreaud, 2010; Toniazzo et al., 2011). Due to a large area of coverage and persistence of stratocumulus clouds, this region significantly affects planetary albedo. It follows that accurate predictions of macrospcopic (e.g., cloud fraction) as well as microscopic (e.g., cloud droplet size) properties of these clouds are important not only from the weather prediction point of view, but also from the climate perspective. Such concerns provided the primary motivation for the VOCALS-REx field experiment.

Stratocumulus decks off the California coast and over the southeastern Pacific often show dramatic changes in the boundary layer cloudiness, from almost solid cloud cover associated with the so-called closed cells to partially-cloudy regions of open cells embedded within the closed-cell expanse. The open-cell structures are called Pockets of Open Cells (POCs) (Stevens et al., 2005) or rifts (Sharon et al., 2006). Their origin is not fully understood, but significant differences in aerosol and cloud microphysical properties between POCs and the surrounding clouds are typically observed (VanZanten and Stevens, 2005; Petters et al., 2006; Sharon et al., 2006; Wood et al., 2008, 2011a). VanZanten and Stevens (2005), Sharon et al. (2006), and Wood et al. (2011a) found that POCs are characterized by enhanced drizzle, although drizzle itself seem insufficient for transition from closed- to open-cell circulations Wood et al. (2011a).

Specific reasons for transitions from closed- to open-cell structure are difficult to determine from observations, and as a result large-eddy simulation (LES) numerical models are often used to investigate the transition (e.g., Savic-Jovcic and Stevens, 2008; Wang and Feingold, 2009a,b; Wang et al., 2010). Model simulations indicate that drizzle can trigger POC formations and subsequently accelerate this process by aerosol depletion, thus pointing to the importance of cloudaerosol interactions. A recent study by Abel et al. (2010) shows that a model with a relatively low spatial resolution (horizontal gridlength of $17 \mathrm{~km}$ ) is able to create cloud-free region within the solid stratocumulus deck, although its relevance to POCs is rather questionable (as noted by Abel et al. (2010) in the last paragraph of Sect. 3.6). Simulations discussed in this paper seem to produce similar structures (see Sect. 4.2). It is unclear whether the mechanisms in the numerical model are the same as in nature, but the presence of cloud-free regions in the low-resolution model indicates that processes other than cloud-aerosol interactions (such as mesoscale waves, for instance) may also be important for transition from closed- to open-cell circulations.

LES models are typically run with gridlengths of a few tens of meters in order to resolve boundary-layer eddies and the stratocumulus cloud that is often only a couple of hundred meters thick. Often even higher vertical resolution is used to better represent the sharp temperature and moisture inversion near the top of the boundary layer and entrainment/mixing processes across the inversion. However, the high spatial resolution implies that only a relatively small area (up to a few hundred $\mathrm{km}^{2}$ ) can be modeled using LES approach. Moreover, the effects of variable (in space and time) large-scale conditions are difficult to impose, and the interactions between small-scale (boundary-layer) processes and the largerscale dynamics (e.g., mesoscale free-tropospheric waves) cannot be considered. Arguably, such interactions can impose significant forcing on the boundary layer, and on the stratocumulus cloud in particular.

This paper presents an application of the off-the-shelf version of the Weather Research and Forecasting (WRF) model (Skamarock et al., 2008) to the 13 November VOCALS-REx case. The WRF model was run in the limited-area mode with the horizontal gridlength of several kilometers and covering a significant fraction of the subtropical southeastern Pacific (SEP). Model results (the lower tropospheric structure in particular) are compared to the observations taken by the BAe-146 UK research aircraft. Sensitivity of model solutions to the number of vertical levels, to the boundary layer and microphysics parameterizations, to the horizontal resolution, and to the model initialization time (to reach the selected model verification period) is also explored. The model does simulate the formation of cloud-free regions in the stratocumulus deck and details of the transition from a cloudy to cloud-free boundary layer are investigated.

The next section discusses the numerical model setup, as well as initial and boundary conditions. The WRF model solutions with different parameterizations are compared to the aircraft observations in Sect. 3. Section 4 discusses simulated mechanisms behind the formation of cloud-free regions. A brief discussion and conclusions are presented in Sect. 5.

\section{Numerical model}

The off-the-shelf version 3.0 of the WRF model (Skamarock et al., 2008) was used to simulate evolution of the stratocumulus clouds over SEP region applying two nested domains. Global Forecast System (GFS) analyses (1 degree horizontal resolution) were used to prescribe initial and boundary conditions for WRF simulations. Motivated by the problems discussed later in the paper, we also used ERA-Interim (ECMWF Reanalysis Interim product, see http: //www.ecmwf.int/research/era/do/get/era-interim) data. The results did not improve significantly, however, and we believe that problems documented in this paper are genuine. SST was interpolated in space and time from 6-hourly GFS values. The WRF model was initialized at 00:00 UTC on 12 November, 00:00 UTC on 10 November, and 00:00 UTC on 5 November, and it was run for $42 / 90 / 234 \mathrm{~h}$. Model output was saved every $15 \mathrm{~min}$ starting from 06:00 on 13 November. The outer model domain for the REF run applied a 9-km grid with $312 \times 212$ gridpoints in the $\mathrm{E}-\mathrm{W}$ and $\mathrm{N}-\mathrm{S}$ 

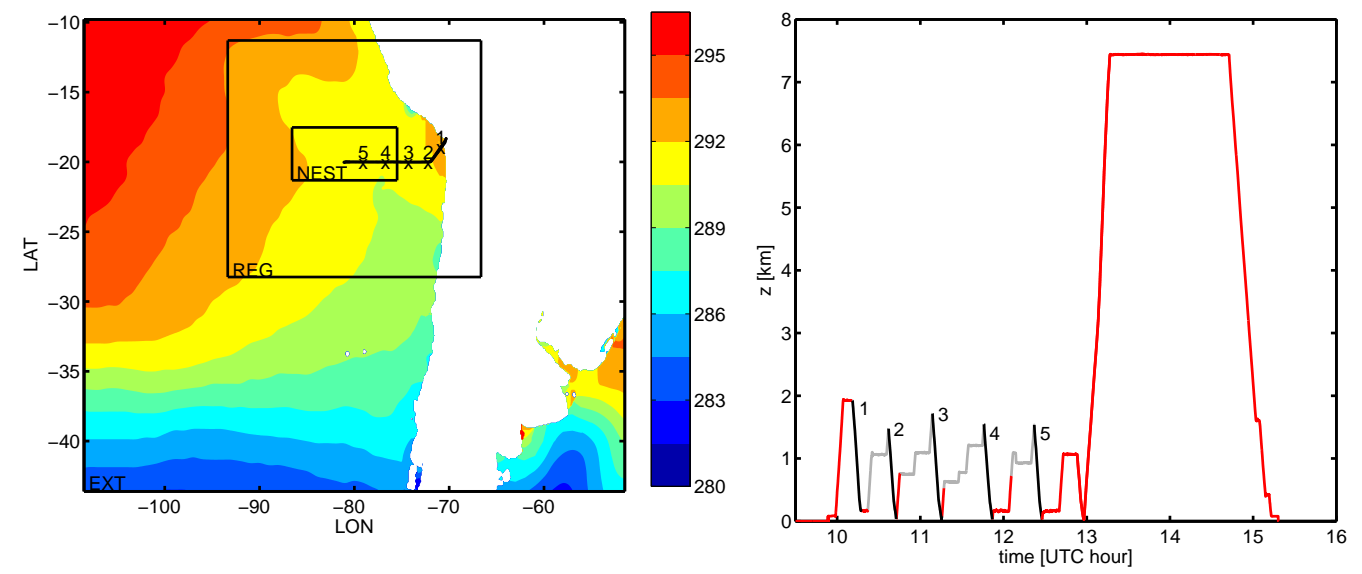

Fig. 1. Aircraft track for the flight B420. Left panel: WRF domains and geographical position of the aircraft together with the SST (colors). Right panel: aircraft altitude versus time for the track shown in the left panel; black lines - profiles used for model evaluation, gray lines additional segments used to document the lower-tropospheric variability within the observed system.

direction, with the centre of the computational domain located at $20^{\circ} \mathrm{S}$ and $80^{\circ} \mathrm{W}$. The inner (NEST) domain used a 3 -km grid with $380 \times 142$ gridpoints. It was placed in such a way that its SW corner was located at a gridpoint $(80,90)$ of the outer domain. The inner domain was initialized from the outer domain solution at 00:00 UTC of 13 November. Extended domain simulation (EXT) also used $9 \mathrm{~km}$ grid size with $624 \times 424$ gridpoints in the $\mathrm{E}-\mathrm{W}$ and $\mathrm{N}-\mathrm{S}$ direction, and the center of the domain was located at $28^{\circ} \mathrm{S}, 80^{\circ} \mathrm{W}$.

The default WRF vertical setup features 36 vertical levels, with the first model level at $29 \mathrm{~m}$ and the vertical gridlength around $343 \mathrm{~m}$ at the height of $1.4 \mathrm{~km}$ (where the cloud top was observed). Such a vertical gridlength is likely to be too large to simulate a realistically cloud-topped boundary layer. To investigate how the model responds to the change of the vertical resolution and the number of vertical levels, two additional simulations were performed, one using 81 levels (eta levels from 0 to 1 by 0.0125 ) and the second one using 121 levels (eta levels from 0 to 1 by 0.00833 ). Applying 81/121 levels results in the height of the first level above the surface of $51 / 34 \mathrm{~m}$, and the vertical gridlength of $120 / 81 \mathrm{~m}$ near the observed cloud top.

Because of the relatively coarse model resolution, especially from the point of view of boundary-layer processes, subgrid-scale parameterizations are likely to play an important role in the simulations. The suite of subgrid-scale parameterizations involve the formulation of surface fluxes, convective transports within the boundary layer as well as cloud microphysics associated with the stratocumulus cloud. In addition, a land-surface model is applied because the computational domain includes a small fraction of the South American continent (see Fig. 1). The following parametrizations were used in the simulations:
- PBL models:

a. The ACM2 (Asymmetric Convective Model, version 2) scheme uses local closure in stable and combined local and non-local closures in unstable conditions (Pleim, 2007).

b. The YSU (Yonsei University) scheme uses a counter-gradient approach to represent transports due to unresolved boundary-layer eddies and an explicit treatment of entrainment processes at the top of the PBL (Hong et al., 2006).

c. The MYJ (Mellor-Yamada-Janjiic) scheme calculates eddy diffusion coefficients from the prognostic TKE equation. This scheme scheme uses Mellor-Yamada Level 2.5 turbulence (local) closure model (Janic, 1990, 1996, 2002).

- Land surface models:

a. NOAH Land Surface Model is a 4 layer soil temperature and soil moisture model with predictive canopy moisture and snow cover (Chen and Dudhia, 2001).

b. Thermal diffusion scheme predicts temperature for 5 soil levels. Soil moisture is specified based on the land use and season (Skamarock et al., 2008).

- Surface layer models:

a. Monin-Obukhov (MO) scheme uses MO similarity theory to derive profiles of the wind and temperature in the surface layer (Paulson, 1970; Dyer and Hicks, 1970; Webb, 1970; Beljaars, 1994; Zhang and Anthes, 1982). 

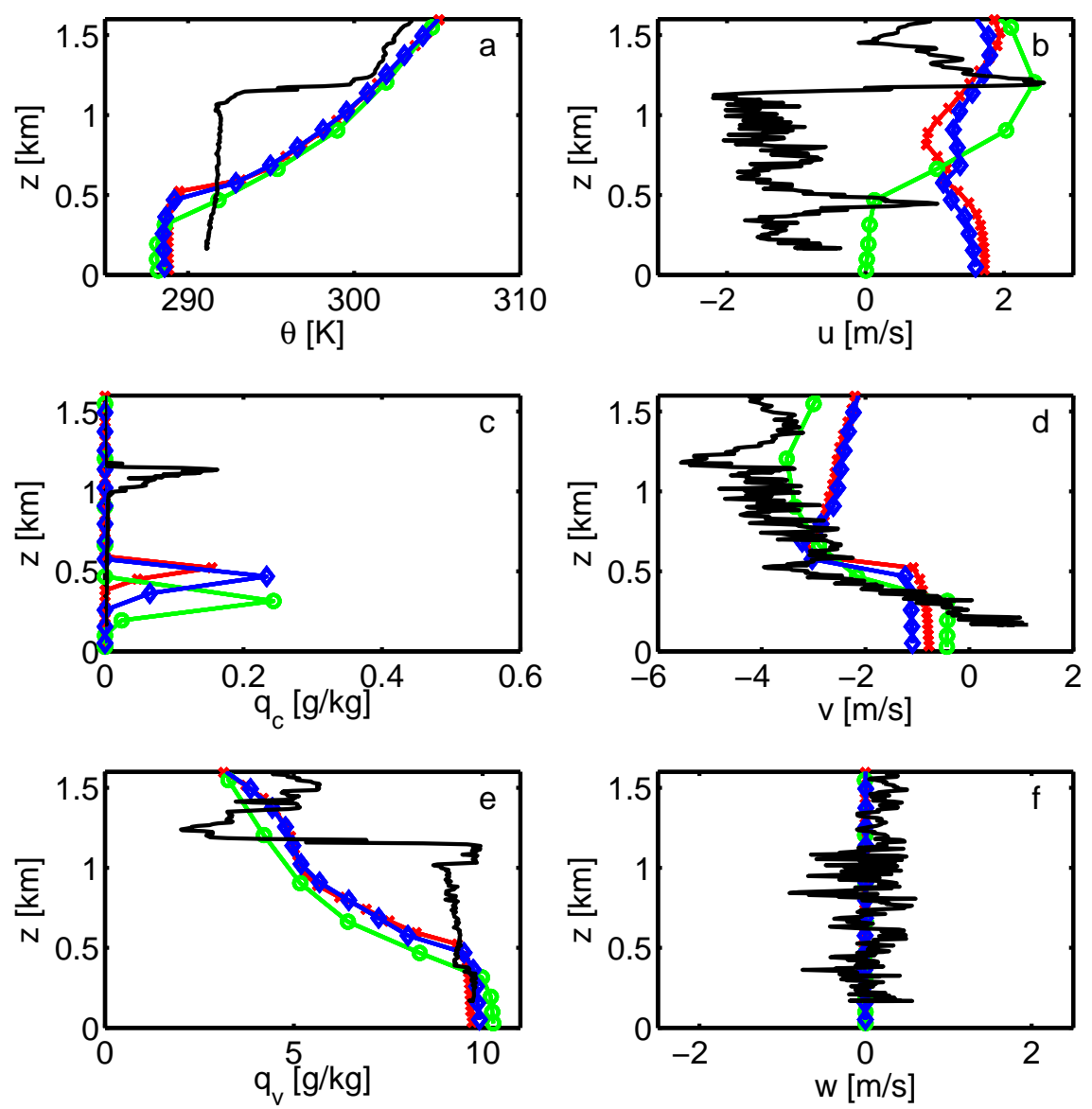

Fig. 2. Model sensitivity to the number of vertical levels for the profile 1; black line - observations, green - model run with 36 vertical levels, blue - model run with 81 vertical levels, red - model run with 121 vertical levels.

b. ETA-model implementation of the MO scheme adds representation of the viscous sub-layer (Janic, 1994, 1996, 2002).

c. Pleim-Xiu scheme is based on similarity theory. A quasi-laminar sublayer is introduced to account for the difference between momentum and scalar fluxes. The MO stability parameter $z / L$ for stable and unstable conditions is derived from the bulk Richardson number. A correction function for very stable conditions is modified to avoid decoupling from the surface. The correction is a function of $z / L$ (the bulk Richardson number) for stable (unstable) conditions (Pleim, 2006).

- Microphysics models:

a. The Kessler war-rain bulk microphysics (Kessler, 1969).

b. The Thompson microphysics predicts mixing ratios of the cloud water, rain, cloud ice, snow, and graupel; and cloud ice number concentration. The scheme uses generalized gamma distribution for each hydrometeor species. The cloud droplet number concentration is assumed $300 \mathrm{~cm}^{-3}$ (Thompson et al., 2004).

c. The Morrison 2-moment bulk microphysics scheme predicts the number concentrations and the mixing ratios of the cloud ice, rain, snow, groupel (or hail) and mixing ratio of cloud droplets; a gamma distribution is used to describe shape of the hydrometeors distribution. Cloud droplet number concentration is assumed $300 \mathrm{~cm}^{-3}$ (Morrison et al., 2009).

- Radiation transfer models:

a. Longwave radiation: The RRTM (Rapid Radiative Transfer Model) is a spectral band scheme using the correlated $\mathrm{k}$ method. This scheme calculates fluxes and cooling rates for the longwave spectral region $\left(10-3000 \mathrm{~cm}^{-1}\right)$. It takes into account water vapor, cloud water, carbon dioxide, ozone, methane, nitrous oxide, and common halocarbons (Mlawer et al., 1997). 

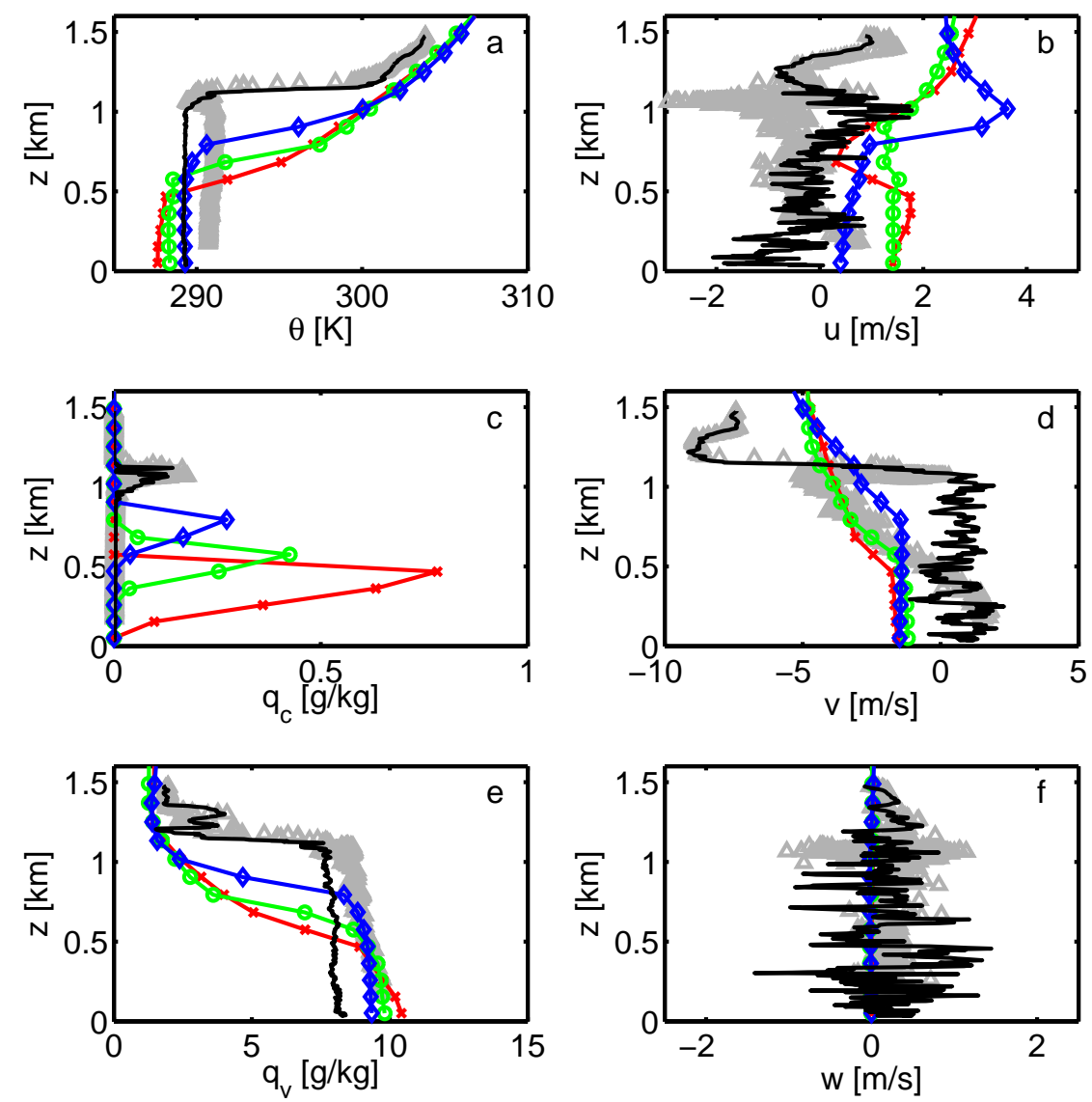

Fig. 3. Model sensitivity to the boundary layer parametrizations for the run with 81 vertical levels and for profile 2; black line - observations, blue - REF, green - SF1, red - SF2; gray points - variability of measurements.

b. Shortwave radiation: The Goddard scheme divides the solar spectrum into 8 bands in the UV and visible range. The scheme accounts for the scattering by the atmospheric gases, clouds and aerosols, and for the absorption by the ozone, water vapor, oxygen and carbon dioxide (Chou and Suarez, 1994).

Table 1 provides specific details concerning parametrizations used in specific simulations.

\section{VOCALS-REx aircraft observations}

Observations used for model evaluation were taken by the UK's BAe-146 research aircraft on 13 November 2008 (flight B420). Figure 1 shows the B420 flight track. Profiles at 5 locations, shown in the figure, were selected for model evaluation. Each of these profiles is obtained through a relatively rapid sampling of the lower troposphere, from above the cloud to near the ocean surface. Each of these profiles is assigned to a spatial location in the closest-in-time model output.
The 1-Hz data collected during the flight are used to obtain profiles of various variables. The potential temperature is derived using the temperature from the Rosemount deiced sensor and the pressure from the aircraft Reduced Vertical Separation Minimum (RVSM) system. The water vapor mixing ratio is derived from the dew point temperature obtained from the TWC (Total Water Content) probe. The cloud water mixing ratio is estimated from the Nevzorov probe, and the air velocity components are obtained from the turbulence probe and GIN (GPS-aided Inertial Navigation) unit. Profiles of these variables are compared to model profiles using the approximate time-and-space location of the model output. In addition, $1-\mathrm{Hz}$ data points are included in selected figures from the gray segments in the right panel of Fig. 1. These data (from either partial profiles or straight horizontal legs) demonstrate the variability of the atmospheric structure in the vicinity of the main profile locations. The difference between the main profile and additional profiles (or partial profiles) is a measure of the representativeness of the profiles and provides a reference for the difference between the model results and observations. 

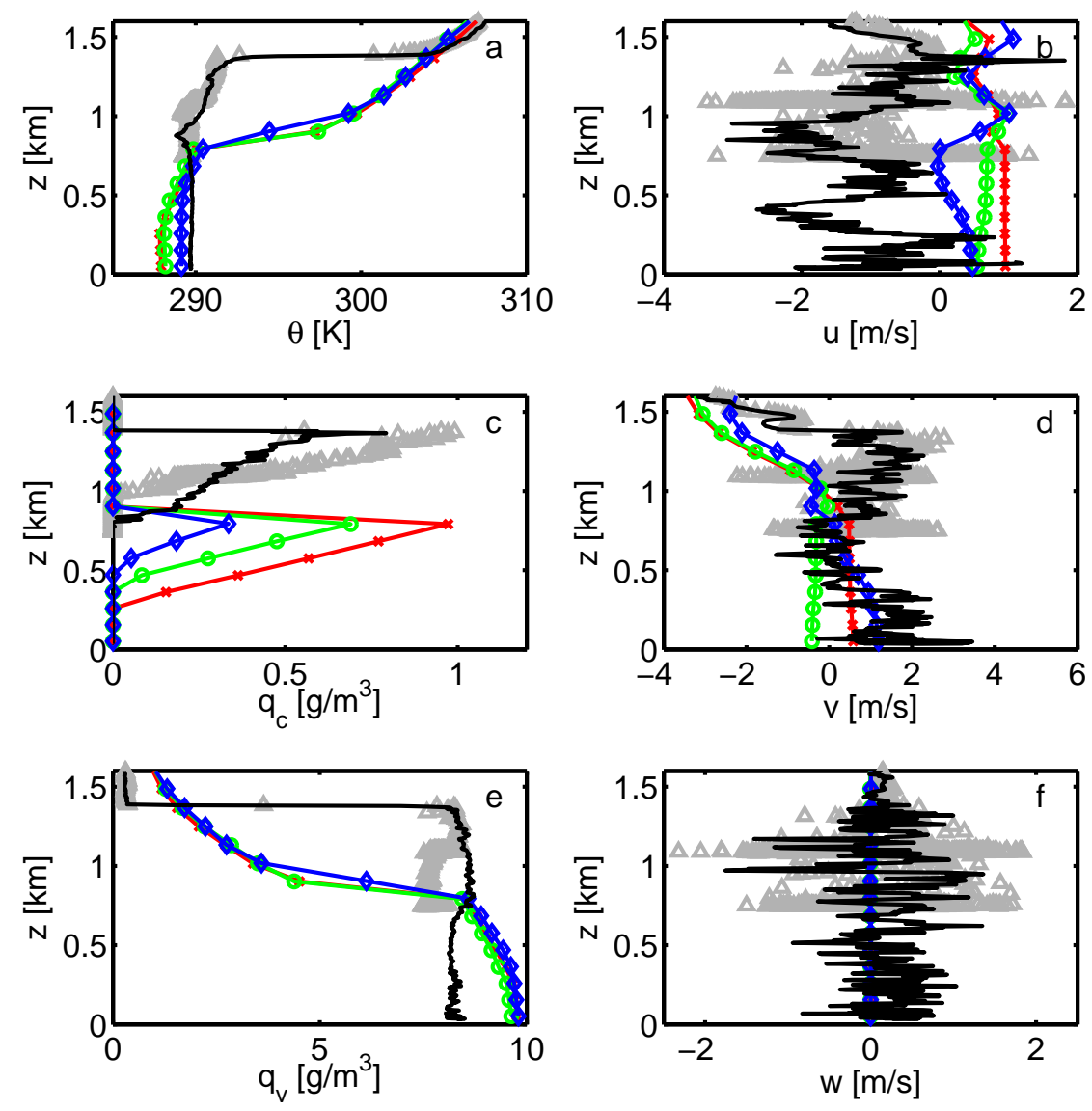

Fig. 4. Model sensitivity to the microphysics parameterizations for the run with 81 vertical levels and for profile 3; blue - REF, green - SM1, red - SM2; gray points - variability of measurements.

\section{Results}

\subsection{Model evaluation and sensitivity}

Figures 2 to 6 show profiles derived from observed variables (temperature, moisture and wind) for locations 1 to 5, respectively, and model results for time/space locations approximately corresponding to the profiles. For each profile, model solutions for different model configurations are shown. Figures 2 to 4 show model solution for simulations started on 12 November for the REF domain. Figure 2 shows model results with different vertical grids (i.e., increasing the number of model levels). Results from simulations applying 81 levels and different parameterizations of boundary-layer processes are shown in Fig. 3 and the impact of using different microphysics parameterizations is documented in Fig. 4. Additional observational data (e.g., partial profiles) as described above are also shown in the figures.

Figures 2 to 4 clearly show that the model typically severely underestimates the depth of the boundary layer. This is consistent with several previous investigations, such as Wyant et al. (2010), Abel et al. (2010), Yang et al. (2011),
Wang et al. (2011). The observed top of the approximately well-mixed boundary layer is between 1 and $1.5 \mathrm{~km}$, but the model predicts the depth of between 0.5 and $1 \mathrm{~km}$. Additional data points (gray symbols) show some variability of temperature and moisture profiles, but not the boundary layer depth. Note that the model does produce stratocumulus cloud despite the much shallower boundary layer. This implies that that the modeled boundary layer has to be either colder or more humid than observed, or both. Inspection of the figures suggests that, typically, the boundary layer is too moist (typically by $1-2 \mathrm{~g} \mathrm{~m}^{-3}$; see Figs. 3, 4, and 5), although in some locations it is also slightly colder (1-2 K in Figs. 2, 3, 4). Considering the poor simulation of the boundary layer depth, it is not surprising that the maximum values of the cloud water mixing ratio $q_{c}$ are different in the observations and in the model solutions. There is, however, no consistent trend, and the model maximum of the cloud water mixing ratio is in some locations higher than observed and sometimes it is lower, with some model profiles showing no cloud water. There are also significant differences between observed and modeled horizontal velocity components. In particular, 

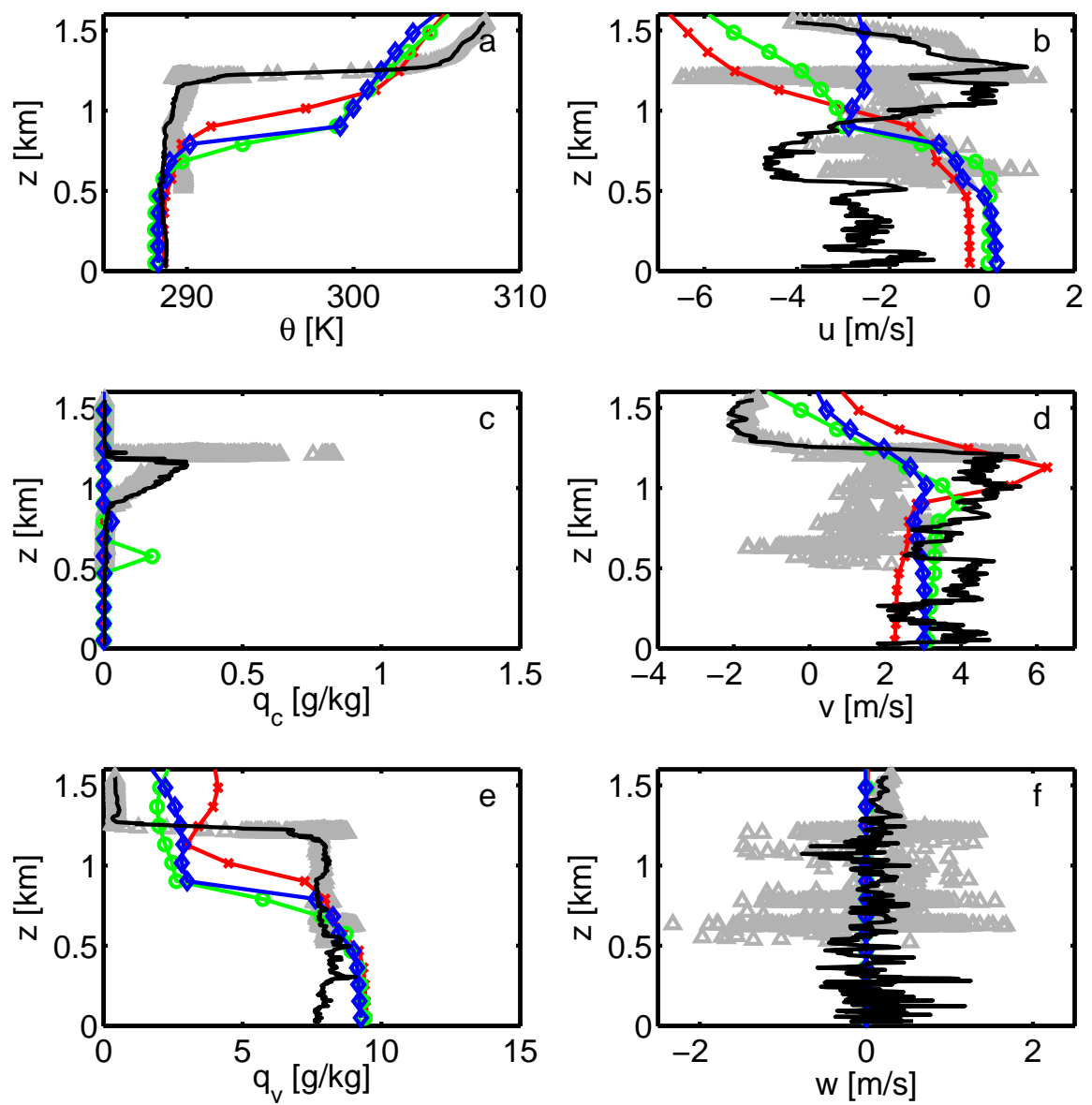

Fig. 5. Model sensitivity to the initialization time for the run with 81 vertical levels and for profile 4; black line - observations, blue 00:00 UTC on 12 November 2008, green - 00:00 UTC on 10 November 2008, red - 00 UTC on 5 November 2008; gray points - variability of measurements.

Table 1. Physical parametrizations used in the simulations with WRF model version 3 (Skamarock et al., 2008) and model domains. Exactly the same parametrizations were used for outer and inner domain for nested runs. The model in the REF configuration for the REG and the EXT simulations was initialized at 00:00 UTC on 12 November 2008, 00:00 UTC on 10 November 2008 and 00:00 UTC on 5 November 2008.

\begin{tabular}{|c|c|c|c|c|c|c|}
\hline & Simulation: & REF & SM1 & SM2 & SF1 & SF2 \\
\hline Physics & & Option (name) & Option (name) & Option (name) & Option (name) & Option (name) \\
\hline mp_physics & & 1 (Kessler) & 8 (Thompson) & 10 (Morrison) & & \\
\hline ra_lw_physics & & 1 (RRTM) & & & & \\
\hline ra_sw_physics & & 2 (Goddard) & & & & \\
\hline sf_sfclay_physics & & 7 (Pleim-Xiu) & & & 1 (Monin-Obukhov) & 2 (Monin-Obukhov (ETA)) \\
\hline sf_surface_physics & & 2 (Noah) & & & 1 (thermal diffusion) & 1 (thermal diffusion) \\
\hline bl_pbl_physics & & 7 (ACM2) & & & $1(\mathrm{YSU})$ & 2 (MYJ TKE) \\
\hline cu_physics & & 0 (cumulus option) & & & & \\
\hline sst_update & & $1(\mathrm{SST})$ & & & & \\
\hline \multicolumn{7}{|l|}{ Domain } \\
\hline $\operatorname{REG}(312 \times 212, \mathrm{dx}=9 \mathrm{~km})$ & & - & - & - & - & - \\
\hline $\operatorname{NEST}(387 \times 141, \mathrm{dx}=3 \mathrm{~km})$ & & - & - & - & - & - \\
\hline $\operatorname{EXT}(624 \times 424, d x=9 \mathrm{~km})$ & & - & & & & \\
\hline
\end{tabular}



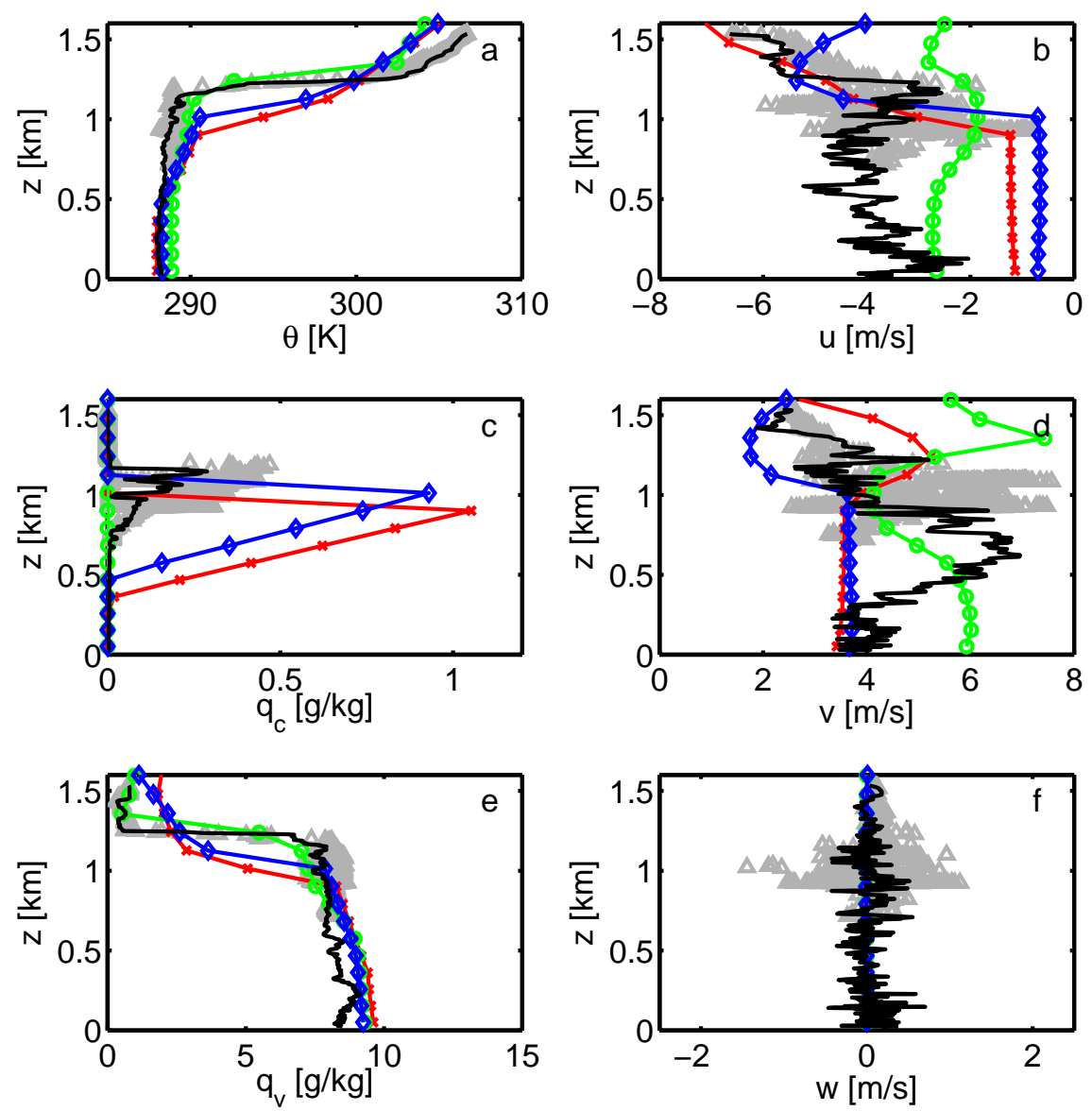

Fig. 6. Model sensitivity to the initialization time for EXT with 81 vertical levels and for profile 5; black line - observations, blue 00:00 UTC on 12 November 2008, green - 00:00 UTC on 10 November 2008, red - 00:00 UTC on 5 November 2008; gray points - variability of measurements.

the observed wind profiles show significantly higher shortvertical-wavelength variability below the mixed-layer inversion. Arguably, such fluctuations come from instantaneous probing of small-scale atmospheric circulations within the boundary layer that the model is not able to simulate because of low spatial resolution. The differences between various observed velocity profiles in the proximity of the same location (i.e., the difference between black and gray symbols) is relatively large. This implies a sizeable time and space variability of the horizontal velocity and suggests that velocity differences between model and observations are less significant than in the case of the temperature and moisture profiles.

Figures 2 to 4 show that none of the combination of parametrizations available in the off-the-shelf WRF model leads to a significant improvement of the boundary height prediction. The model shows the largest sensitivity to the boundary layer parameterizations and those used in the REF simulation (see Table 1) give the highest (and thus closest to observations) boundary layer height.
Increasing the horizontal resolution from $9 \mathrm{~km}$ (outer domain) to $3 \mathrm{~km}$ (inner domain) also has little impact on the solutions, with the effect on the profiles similar to that due to the vertical resolution (not shown). Note that only profiles at locations 4 and 5 could be compared for the nested simulations because other locations were outside of the inner domain.

Simulations with different model initialization times and different domain size (with the results shown on Figs. 5 and 6) suggest that the model can in some cases better predict the boundary layer height, but there is no consistent trend. For instance, for the profile 4, initializing the model on 5 November improves the prediction when compared to the simulation initialized on 10 November, but when the domain size is increased and the profile 5 is considered, the opposite is observed.

The overall conclusion from the comparison between observations and model simulations (highlighted in Figs. 2 to 6 ) is that the model was unable to simulate the observed depth of the well-mixed stratocumulus-topped subtropical 

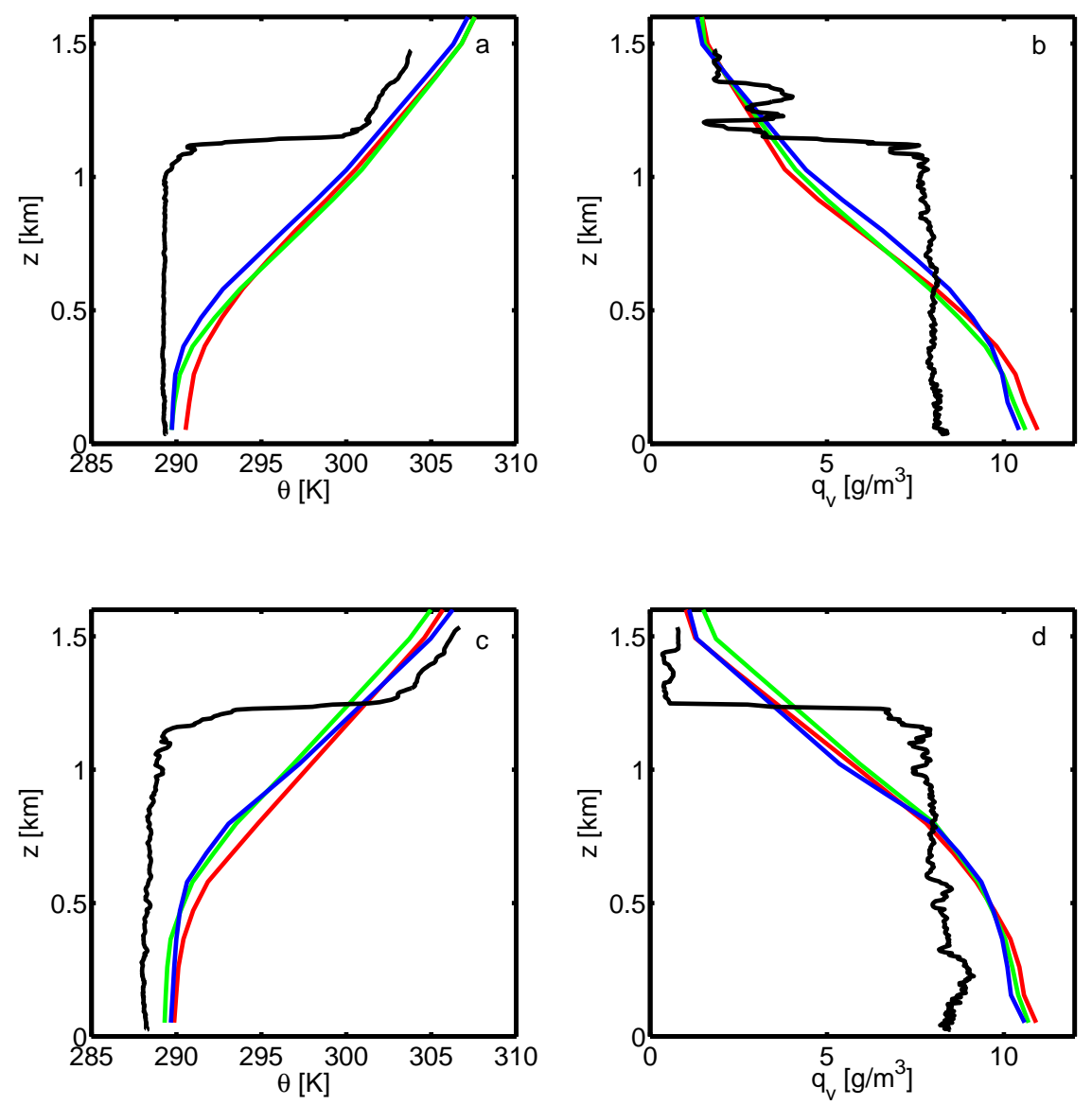

Fig. 7. GFS profiles of the $\theta$ and $q_{v}$ for location 2 (upper panels) and location 5 (lower panels) for 12 November for 00:00 UTC - blue, 12 November for 12:00 UTC - green, and 13 November for 00:00 UTC - red. Black lines show profiles measured by the BAe-146.

boundary layer off the South American continent. We believe that there are two causes of this problem. Firstly, the input of GFS dataset used to set initial and lateral boundary conditions for WRF simulations already has a deficient representation of the lower tropospheric structure. Secondly, neither of the boundary layer schemes available in the WRF model version we used was capable of rising the inversion height to levels comparable to observations.

The problem with the GFS input data is documented in Fig. 7 which shows the comparison between aircraft observations in locations 2 and 5 (shown previously in Figs. 3 and 6 , respectively) and the GFS profiles on 12 November (00:00 and 12:00 UTC) and 13 November (00:00 UTC). Clearly, the GFS profiles show a boundary layer that is less than half as deep as aircraft observations suggest. Similar conclusion is reached inspecting the ERA Interim data used in one of the simulations. Although the inversion is better defined and its height is larger than in the GFS data (around $0.5 \mathrm{~km}$ for location 2 and around $0.7 \mathrm{~km}$ for location 5), it is still significantly lower than in the observations. It is our conjecture that lack of observations over SEP region that can be assimilated into the data assimilation system, in combination with deficiencies of the boundary-layer scheme (perhaps similar to problems with the WRF schemes as discussed below), lead to a significantly shallower boundary layer.

Arguably, the WRF model should be able to increase the depth of the boundary layer from the GFS values used as initial and lateral boundary conditions, especially when the model over the ocean is forced with the SSTs from the GFS analysis as is the case here. Indeed, inspection of the inversion height predicted by the WRF model (not shown) documents that the inversion height increases from the GFS values near the south-eastern inflow boundary of the inner domain (a few hundred meters) to values larger than $1 \mathrm{~km}$ at the western edge of the inner domain (beyond reach of the BAe-146 aircraft). The primary reason is the increase of the SST along the south-easterly flow in the inner domain (cf. Fig 1). However, as illustrated by the comparison between model output and BAe-146 observations, a boundary layer is still too shallow in the simulations. This points to deficiencies in boundary layer parametrizations available in the WRF model. A comparison between the height of the 

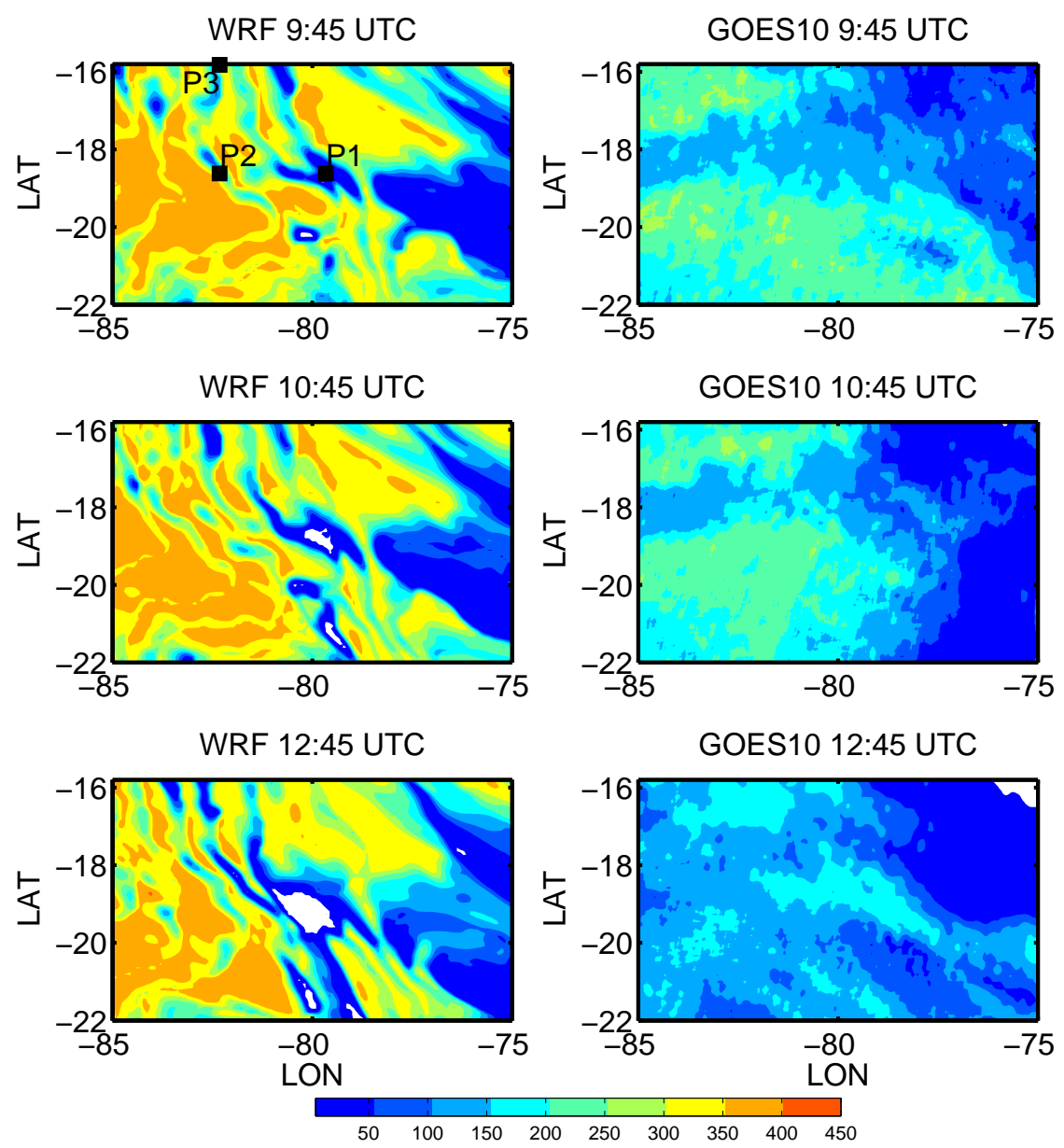

Fig. 8. Left column: LWP for the model solution with 121 vertical levels for times 09:45, 10:45, 12:45 UTC. Right column: GOES10 LWP for the same times. Positions of column P1, P2, and P3 are also marked.

boundary-layer inversion (estimated from the vertical gradient of the lower-tropospheric potential temperature profiles) and the boundary layer depth applied in the boundary layer scheme (one of many variables in WRF output) shows that the latter is significantly smaller than the former. In fact, the boundary layer depth used in the boundary-layer scheme is typically close to the height of the cloud base rather than the cloud top.

\subsection{Formation of mesoscale cloud-free regions}

Despite simulation deficiencies discussed above, an analysis focusing on the evolution of stratocumulus clouds as simulated by the limited-area WRF model was undertaken. The model simulation with 121 levels and parameterizations as in REF was used to investigate simulated development of mesoscale cloud-free regions. We use the liquid water path (LWP), the vertical integral of the cloud water content, as a convenient measure of the total condensate in each model column. Figure 8 shows spatial distribution of the LWP at
09:45, 10:45 and 12:45 UTC (left panels) for a part of the computational domain. Corresponding distributions derived from GOES10 satellite radiances (using the method of Minnis et al. (2011) as described in Wood et al. (2011b) and averaged from GOES10 1-km resolution to model 9-km resolution) are shown in the right-hand panels. In both model simulations and in observations, LWP increases as one moves westward away from the South American continent. However, the model tends to produce higher LWP than observed in the western half of the domain, 300 to $400 \mathrm{~g} \mathrm{~m}^{-2}$ versus the observed 100 to $200 \mathrm{~g} \mathrm{~m}^{-2}$. Perhaps not surprisingly, the spatial variability is different in the observations and in the model, with NW-SE "streets" apparent in the model and finer-scale structures present in the observations. The latter is even more evident in the original GOES10 data, that is, prior to the spatial averaging (not shown). Also, satellite data seem to show a significant decrease of the LWP between 09:45 and 12:45 UTC. This effect is significantly weaker (perhaps absent) in the WRF model results. 

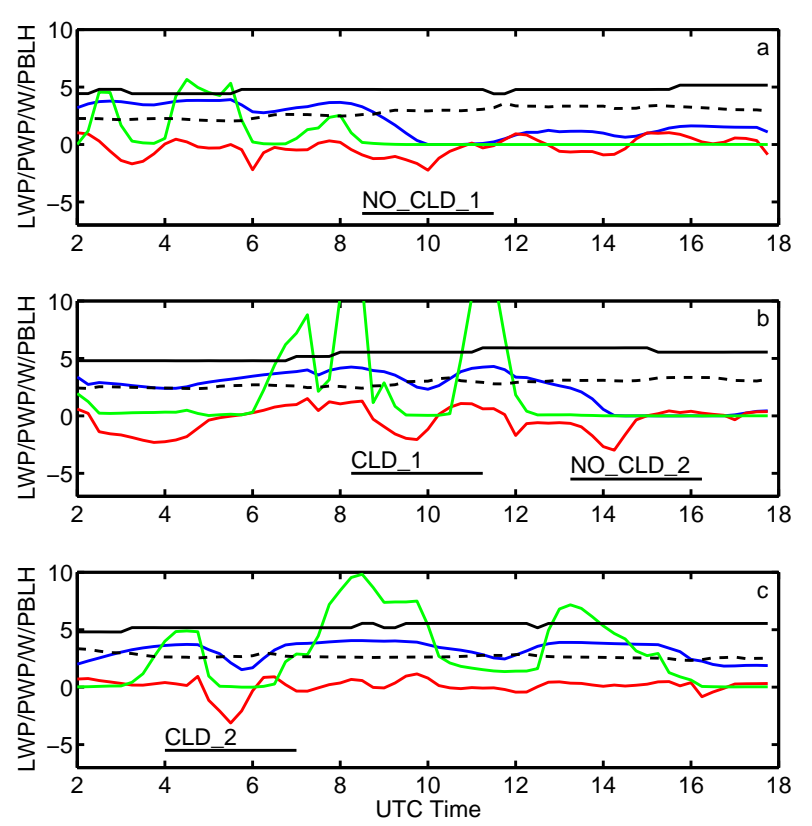

Fig. 9. Evolution in time of LWP (in $\mathrm{g} \mathrm{m}^{-2}$ ) $\times 0.01$ (blue), PWP (in $\left.\mathrm{g} \mathrm{m}^{-2}\right) q_{r}$ (green), $w_{\text {int }}$ (in $\mathrm{cm} \mathrm{s}^{-1}$ ) (red), inversion height (in m) $\times 0.005$ (black solid), and boundary layer height (in m) $\times 0.005$ (black dashed) for (a) P1 (-79.66,18.62), (b) P2 (-82.32, - 18.62), (c) P3 (-82.32, -15.82).

Despite different spatial patterns, both observations and simulations show regions of reduced LWP embedded within larger-scale regions of higher LWP. In the model, unlike in the observations, a few cloud-free regions develop over time. One of these forms around 10:00 UTC near $18^{\circ} \mathrm{S}$ and $80^{\circ} \mathrm{W}$, and grows with time reaching a size between 20000 and $30000 \mathrm{~km}^{2}$ by 12:45 UTC. No cloud clearing as pronounced as this in the numerical model is present in satellite LWP, but there are areas with low LWP, south-east from the modelsimulated clearing (i.e., near $21^{\circ} \mathrm{S}$ and $78^{\circ} \mathrm{W}$ ).

It is unclear whether the structures produced by the model and those observed have a similar origin. The complexity of the interactions between the simulated processes (especially those resolved and those parameterized) makes process-level understanding of model results a significant challenge. As illustrated by the model results shown in Fig. 8, the large-scale pattern does not move significantly in space and thus the analysis can be carried out for fixed spatial locations. Three locations were chosen from the computational domain. The first one (P1, see Fig. 8) is located at $18.62^{\circ} \mathrm{S}$ and $79.66^{\circ} \mathrm{W}$ where the cloud-free region first develops. The second location (P2) at $18.62^{\circ} \mathrm{S}$ and $82.32^{\circ} \mathrm{W}$ is to the west of $\mathrm{P} 1$ and the cloud-free region there develops later than for $\mathrm{P} 1$. The third location (P3) is to the north-west of $\mathrm{P} 1,15.82 \mathrm{~S}$ and $82.32^{\circ} \mathrm{W}$. At P3, the cloud-free region does not develop within the analysed time period. These locations are marked in Fig. 8. Figure 9 shows the evolution (between 02:00 and 18:00 UTC) of parameters of interest for the cloud-free region development. These include the LWP and precipitation water path (PWP), the vertical velocity averaged between 0.5 and $1.2 \mathrm{~km}$ (referred to as $w_{\text {int }}$ ), the inversion height (defined as the level of the maximum lower-tropospheric potential temperature gradient) and the boundary layer height as predicted by the WRF model. Evolution of the latter two parameters illustrate the issues already highlighted in the previous discussion. As the figure shows, periods of significant drizzle (high PWP) correspond to increased LWP as one might expect.

Figure 9a shows the evolution of the parameters for location P1. A cloud-free region NO_CLD_1 develops at this location at around $1000 \mathrm{UTC}$ and lasts only about $1.5 \mathrm{~h}$. As indicated by the PWP, drizzle is present at this location up to $1.5 \mathrm{~h}$ before cloud disappearance, but the disappearance seems to result from a strong (up to about $4 \mathrm{~cm} \mathrm{~s}^{-1}$; not shown) subsidence in the model column. One cannot rule out the possibility that subsidence was initiated by drizzle evaporation because the subsidence starts at the end of the drizzle period. However, the subsidence amplifies during the period without drizzle and only then is the LWP reduced to zero. Similar evolution is apparent for the P2 location (Fig. 9b) between 12:00 and 16:00 UTC (region NO_CLD_2), with the subsidence intensifying after a period with nonzero PWP. For the two other periods CLD_1 in Fig. 9b and CLD_2 in Fig. $9 \mathrm{c}$ with significant subsidence, the cloud-free regions do not develop. The subsidence, with magnitudes comparable to NO_CLD_1 and NO_CLD_2, only leads to the reduction of LWP and suppression of drizzle. Note that the subsidence phase associated with the CLD_1 is separated from the similar evolution during the NO_CLD_2 phase by a significant updraft, cloud deepening, and drizzle. In general, Fig. 9 shows a significant variability and tight coupling between lower-tropospheric vertical velocity, cloud water and drizzle. Periods of significant lower tropospheric updrafts typically lead to cloud deepening and enhanced drizzle, whereas periods of significant downdrfats occasionally lead to complete cloud evaporation and formation of cloud-free regions.

Coupling illustrated in Fig. 9 may be associated with mescoscale variability, for instance, due to gravity or inertiagravity waves, affecting processes near the boundary layer top. This is further illustrated by Fig. 10 which shows vertical and horizontal cross-sections of the simulated lower troposphere with the emphasis on the flow and cloud structures. As Fig. 9 suggest, formation of cloud-free regions in the model involves a period of significant drizzle followed by a strong lower-tropospheric subsidence. To illustrate spatial variability that accompanies temporal variability illustrated in Fig. 9, we show in the left panels of Fig. 10, the evolution of the LWP contour of $1 \mathrm{~g} \mathrm{~m}^{-2}$ (thick black line) and the vertical velocity at about $1 \mathrm{~km}$ height (model level 14; colors). Additionally, the direction of the horizontal wind for model levels below and above the boundary layer inversion (model levels 12 and 19; about 0.8 and $1.3 \mathrm{~km}$ height) are shown using gray and magenta arrows, 

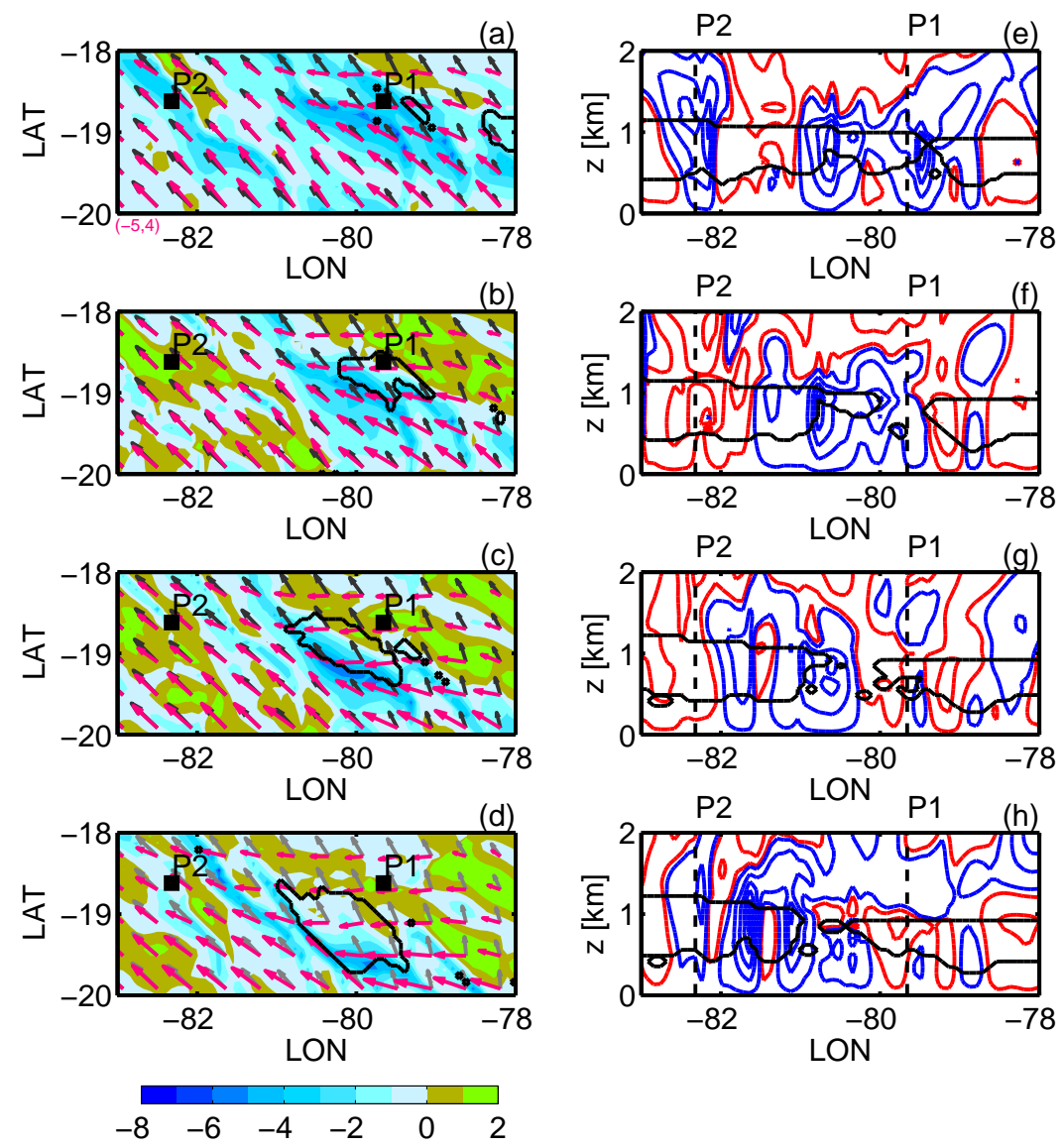

Fig. 10. Left panels: vertical velocity (in color) on level $14(z=1000 \mathrm{~m})$ and $1\left(\mathrm{~g} \mathrm{~m}^{-2}\right)$ LWP contour (black line) for times 9.15, 10.15, 11.15, 12.15 UTC (panels a-d); gray arrows: horizontal velocity on level $12(z=780 \mathrm{~m})$, magenta arrows: horizontal velocity above the boundary layer on level $19(z=1300 \mathrm{~m})$. Red numbers below the upper left panel define the velocity vector in the lower left corner of the panel. Right panels: vertical cross section through the computational domain for the latitude 18.62S. Red/blue: contours of the positive/negative vertical velocity starting from $0.2 /-0.2 \mathrm{~cm} \mathrm{~s}^{-1}$, every $1 \mathrm{~cm} \mathrm{~s}^{-1}$. Black line: contour of the $q_{c}=0.1 \mathrm{~g} \mathrm{~kg}^{-1}$. Positions of column P1 and P2 are shown in the left panels.

respectively. The figure shows that the model simulates an organized mesoscale pattern of lower-tropospheric vertical velocity (updrafts and downdrafts), approximately along the SE-NW direction. Cloud-free regions form in subsidence areas. The cloud-free region in the center of the domain expands as the subsidence in this area expands. There is also a significant change of the horizontal velocity direction between the boundary layer and the free troposphere, covering most of the domain shown, with the wind changing direction from S-E (within the boundary layer) to E above. A strong subsidence (up to $6 \mathrm{~cm} \mathrm{~s}^{-1}$ ) seems to be associated with the wind convergence above the boundary layer.

The right panels of Fig. 10 show vertical cross sections along the latitude of $18.62^{\circ} \mathrm{S}$. The vertical velocity associated with cloud clearings is mostly limited to the lowest $2 \mathrm{~km}$ of the atmosphere. The pattern of the vertical velocity seems to be directly associated with the cloud depth pattern, with regions of updraft/downdraft coinciding with deeper/shallower clouds. As already illustrated by horizontal cross-sections in the left hand panels, the vertical velocity pattern does not seem to be associated with any coherent structure, such as gravity or inertia-gravity waves.

The evolution of lower-tropospheric profiles within the two regions (NO_CLD_1 and CLD_2) are presented in Figs. 11 and 12, respectively. The profiles are shown in 30-min intervals starting at 08:30/04:00 UTC for NO_CLD_1/CLD_2. There are a few common features for all the profiles. Firstly, the boundary layer is approximately well-mixed for total water and liquid water potential temperature and for the horizontal wind components. Secondly, the extrema of the lower-tropospheric vertical velocity are typically located near the cloud top. The maxima seem similar for the NO_CLD and CLD profiles. Perhaps the most significant differences are in the depth of the cloud layer, shallower in the NO_CLD case (Fig. 11) and deeper in the CLD case (Fig. 12). Presence/absence of drizzle in CLD/NO_CLD 

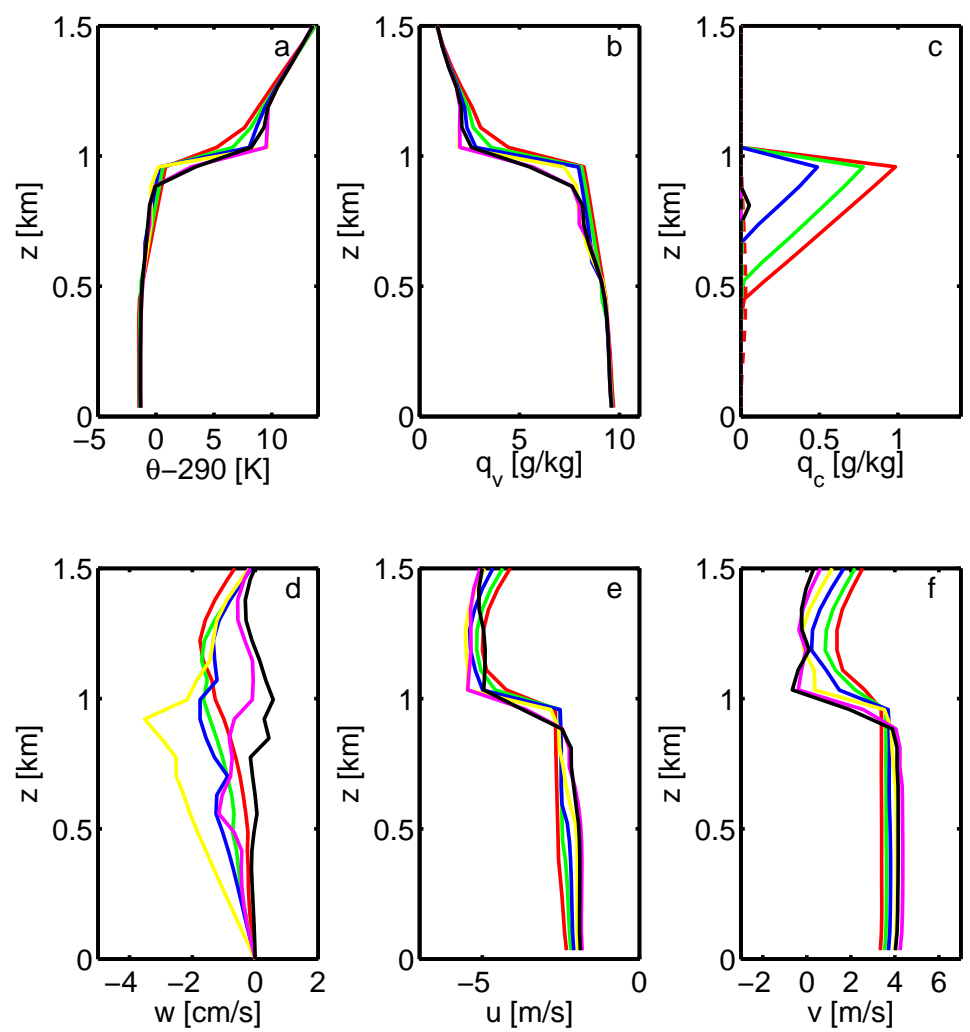

Fig. 11. Profiles of $\theta(\mathbf{a}), q_{v}(\mathbf{b}), q_{c}(\mathbf{c}), w(\mathrm{~d}), u$ (e), $v$ (f) for location P1 for times 08:30 (red), 09:00 (green), 09:30 (blue), 10 (yellow), 10:30 (magenta), 11:00 (black) UTC.

cases is arguably associated with deeper/shallower cloud layer and thus does not seem to play role in the formation of the cloud-free region, as argued earlier in the paper.

\section{Discussion and conclusions}

We presented an application of the off-the-shelf version 3.0 of the WRF model to a limited-area case-study-type simulations of stratocumulus clouds over the South-Eastern Pacific during the VOCALS-REx field project. Because of the relatively coarse horizontal and vertical resolution when compared to LES modeling, the simulations feature interactions between resolved processes, such as the mesoscale dynamics, and processes that have to be parameterized (boundary layer transports, cloud processes, etc.). Simulated lower tropospheric structure and cloud characteristics were compared to the observations collected by the UK's BAe-146 research aircraft. We also analysed the simulated formation of cloudfree regions, anticipating that physical mechanisms simulated by the WRF model have some relevance to the Pockets of Open Cells (POCs) observed in nature over the subtropical Pacific ocean off the coast of North and South America.

The WRF-predicted profiles of potential temperature, cloud water mixing ratio, water vapor mixing ratio and horizontal velocities showed significant differences from those observed during the B420 flight on 13 November 2008. Although there was a significant variability of the observed profiles (the largest for the horizontal velocity components within the boundary layer), the variability does not explain the systematic differences in the boundary layer height between the observations and simulations. Overall, significant underprediction of the height is consistent with previous limited-area simulations of cloud-topped marine boundary layer (e.g., Wyant et al., 2010; Abel et al., 2010; Yang et al., 2011; Wang et al., 2011). In our case, the underprediction results from a combination of two factors. Firstly, the boundary layer in the input data that provided the initial and inflow boundary conditions (i.e., the GFS 1 degree analyses or ERA Interim) was way too shallow, arguably because the deficiencies of the data assimilation systems and sparse (or non-existing) boundary-layer data over the south-eastern Pacific. The second factor concerns deficiencies of the boundary layer schemes available in the WRF model. Analysis of the WRF output suggested the boundary layer schemes diagnosed boundary layer height near the cloud base rather than near the cloud top, as one might expect for approximately well-mixed (in the sense of conserved moist variables) marine boundary layer.

Model solutions improved little (and typically only far from the shore) when the number of model levels was 

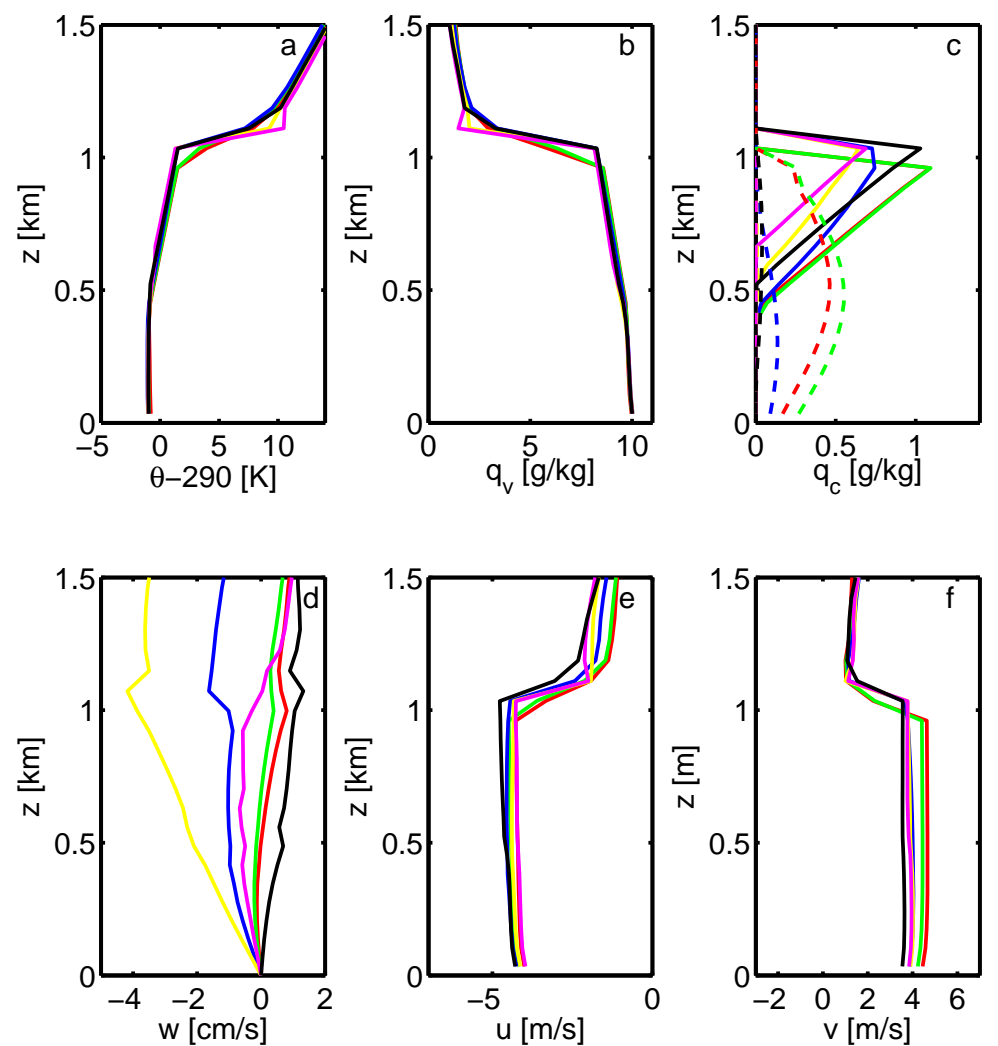

Fig. 12. Profiles of $\theta$ (a), $q_{v}$ (b), $q_{c}$ (c), $w$ (d), $u$ (e), $v$ (f) for P3 for times 04:00 (red), 04:30 (green), 05:00 (blue), 05:30 (yellow), 06:00 (magenta), 06:30 (black) UTC.

increased from 36 to 81 , consistent with results discussed by Wang et al. (2011). When the horizontal gridlength was reduced from 9 to $3 \mathrm{~km}$, there was almost no change in boundary layer height. This is in contrast to the results presented by by Wang et al. (2011), where improvement with the increasing horizontal resolution $(45 \mathrm{~km}, 15 \mathrm{~km}, 5 \mathrm{~km})$ was reported. Moreover, the results changed little when different boundarylayer and cloud microphysics parametrizations available in the particular version of the WRF model were used. Increasing domain size and extending simulations time tends to increase boundary layer height only for profiles observed away from the shore, with no improvement for the profiles close to the shore.

Despite these deficiencies, the model did produce cloudfree regions as observed by the aircraft on that day. An additional analysis was carried out for three different locations to highlight processes involved in the formation of cloud-free regions. It was shown that the regions were created as a result of the interaction between regions of lower-tropospheric mesoscale subsidence (a maximum downdraft velocity of a few $\mathrm{cm} \mathrm{s}^{-1}$ ) with parameterized cloud-topped boundary layer processes, such as boundary-layer transports, condensation/evaporation, and entrainment. Drizzle, limiting the cloud liquid water content and cloud water path, might have played some role, but it typically ceased one to two hours before the cloud-free region formed.

The impact of the lower-tropospheric mesoscale vertical velocity field on the marine boundary layer documented here seems consistent with observational study of Allen et al. (2011), where a passage of a mesoscale inertia-gravity wave was argued to be responsible for the transition from fully-cloudy closed-cell circulation patterns to the partiallycloudy open-cell structures. However, Allen et al. (2011) hypothesized a different chain of events leading to the transition. They argued that the deepening of the cloud field leads to more drizzle, and the enhanced drizzle results in the transition. Such a picture is consistent with previous LES studies (e.g., Savic-Jovcic and Stevens, 2008) suggesting that strongly-drizzling stratocumulus with closed-cell circulations gradually transitions into open cells. Small-scale dynamical processes associated with the drizzle fallout and evaporation, unresolved in the limited area model, are likely to be key in the transition. In contrast, the WRF simulations discussed here seem to show direct evaporation of the cloud due to lower-tropospheric mesoscale subsidence with little, if any, role of drizzle. It is thus not surprising that the formation of cloud-free regions was relatively insensitive to the parameterization of cloud microphysics. 
The model results reported here call for further studies using LES models applying time-evolving vertical velocity due to lower-tropospheric waves as in Allen et al. (2011) or mesoscale features simulated in the current study. Such simulations should document if the evolution hypothesized in Allen et al. (2011) and simulated by limited-area model reported here are indeed reproduced by a model that resolves boundary-layer dynamics as well as small-scale cloud and drizzle processes. We hope to report on such simulations in the near future.

Acknowledgements. This work was supported by NERC funding for the VOCALS-REx project, NCAS computer time on HECToR, and BADC data centre. WWG was partially supported by the NOAA grant NA08OAR4310543 and DOE ARM grant DE-FG0208ER64574. LWP data derived from GOES10 were provided by P. Minnis. ECMWF ERA-Interim data used in this study have been provided by ECMWF.

Edited by: C. R. Mechoso

\section{References}

Abel, S. J., Walters, D. N., and Allen, G.: Evaluation of stratocumulus cloud prediction in the Met Office forecast model during VOCALS-REx, Atmos. Chem. Phys., 10, 10541-10559, doi:10.5194/acp-10-10541-2010, 2010.

Allen, G., Vaughan, G., Coe, H., and Minnis, P.: Gravity waves observed as a causal mechanism for transition from closed to open cellular convection in the remote South East Pacific, to be submitted, 2011.

Beljaars, A.: The parameterization of surface fluxes in large-scale models under free convection, Quart. J. Roy. Meteor. Soc., 121, 255-270, 1994.

Chen, F. and Dudhia, J.: Coupling an advanced land-surface/ hydrology model with the Penn State/ NCAR MM5 modeling system. Part I: Model description and implementation, Mon. Weather Rev., 129, 569-585, 2001.

Chou, M.-D. and Suarez, M. J.: An efficient thermal infrared radiation parameterization for use in general circulation models, NASA Tech. Memo., 104606, 3, 85 pp., 1994.

Dyer, A. J. and Hicks, B. B.: Flux-gradient relationships in the constant flux layer, Quart. J. Roy. Meteor. Soc., 96, 715-721, 1970.

Hong, S., Noh, Y., and Dudhia, J.: A new vertical diffusion package with an explicit treatment of entrainment processes, Mon. Weather Rev., 134, 2318-2341, 2006.

Janic, Z. I.: The step-mountain coordinate: physical package, Mon. Weather Rev., 118, 1429-1443, 1990.

Janic, Z. I.: The step-mountain eta coordinate model: further developments of the convection, viscous sublayer and turbulence closure schemes, Mon. Weather Rev., 122, 927-945, 1994.

Janic, Z. I.: The surface layer in the NCEP Eta Model, Norfolk, VA, 19-23 August, Amer. Meteor. Soc., Boston, MA, 1996.

Janic, Z. I.: Nonsingular Implementation of the Mellor-Yamada Level 2.5 Scheme in the NCEP Meso model, NCEP Office Note, No. 437, 61, 2002.
Kessler, E.: On the distribution and continuity of water substance in atmospheric circulation, Amer. Meteor. Soc, 32, 84 pp., 1969.

Minnis, P., Sun-Mack, S., Young, D. F., Heck, P. W., Garber, D. P., Chen, Y., Spangenberg, D. A., Arduini, R. F., Trepte, Q. Z., Smith Jr., W. L., Ayers, J. K., Gibson, S. C., Miller, W. F., Chakrapani, V., Takano, Y., Liou, K.-N., Xie, Y., and Yang, P.: CERES Edition-2 cloud property retrievals using TRMM VIRS and Terra and Aqua MODIS data, Part I: Algorithms, IEEE Trans. Geosci. Remote Sens., in press, 2011.

Mlawer, E. J., Taubman, S. J., Brown, P. D., Iacono, M. J., and Clough, S. A.: Radiative trans-fer for inhomogeneous atmosphere: RRTM, a validated correlated-k model for the longwave., J. Geophys. Res., 102, 16663-16682, 1997.

Morrison, H., Thompson, G., and Tatarskii, V.: Impact of cloud micrpohysics on the development of trailing stratiform precipitation in a s:1imulated squall line: Comparison of one- and twomoment schemes., Mon. Weather Rev., 137, 991-1007, 2009.

Paulson, C. A.: The mathematical representation of wind speed and temperature profiles in the unstable atmospheric surface layer, J. Appl. Meteorol., 9, 857-861, 1970.

Petters, M. D., Snider, J. R., Stevens, B., Vali, G., Faloona, I., and Russell, L. M.: Accumulation mode aerosol, pockets of open cells, and particle nucleation in the remote subtropical $\mathrm{Pa}$ cific marine boundary layer, J. Geophys. Res., 111, D02206, doi:10.1029/2004JD005694, 2006.

Pleim, J. E.: A simple, efficient solution of flux-profile relationships in the atmospheric surface layer, J. Appl. Meteorol. Climatol., 45, 341-347, 2006.

Pleim, J. E.: A combined local and nonlocal closure model for the atmospheric boundary layer. Part I: Model description and testing., J. Appl. Meteorol. Climatol., 46, 1383-1395, 2007.

Rahn, D. A. and Garreaud, R.: Marine boundary layer over the subtropical southeast Pacific during VOCALS-REx - Part 1: Mean structure and diurnal cycle, Atmos. Chem. Phys., 10, 4491-4506, doi:10.5194/acp-10-4491-2010, 2010.

Savic-Jovcic, V. and Stevens, B.: The structure and mesoscale organization of precipitating stratocumulus, J. Atmos. Sci., 65, 15871605, 2008.

Sharon, T. M., Albrecht, B. A., Jonsson, H. H., Minnis, P., Khaiyer, M. M., van Reken, T. M., Seinfeld, J., and Flagan, R.: Aerosol and Cloud Microphysical Characteristics of Rifts and Gradients in Maritime Stratocumulus Clouds, J. Atmos. Sci., 63, 983-997, 2006.

Skamarock, W. C., Klemp, J. B., Dudhia, J., Gill, D. O., Barker, D. M., Duda, M. G., Huang, X.-Y., Wang, W., and Powers, J. G.: A Description of the Advanced Research WRF Version 3, National Center for Atmospheric Research, 2008.

Stevens, B., Vali, G., Comstock, K., Wood, R., VanZanten, M. C., Austin, P. H., Bretherton, C. S., and Lenschow, D. H.: Pockets of open cells and drizzle in marine stratocumulus, Bull. Amer. Meteorol. Soc., 86, 51-57, 2005.

Thompson, G., Rasmussen, R. M., and Manning, K.: Explicit forecasts of winter precipitation using an improved bulk microphysics scheme. Part I: Description and sensitivity analysis., Mon. Weather Rev., 132, 519-542, 2004.

Toniazzo, T., Abel, S. J., Wood, R., Mechoso, C. R., Allen, G., and Shaffrey, L. C.: Large-scale and synoptic meteorology in the South-East Pacific during the observations campaign VOCALSREx in Spring 2008, Atmos. Chem. Phys. Discuss., 11, 225-288, 
doi:10.5194/acpd-11-225-2011, 2011.

VanZanten, M. C. and Stevens, B.: Observations of the Structure of Heavily Precipitating Marine Stratocumulus, J. Atmos. Sci., 62, 4327-4342, 2005.

Wang, H. and Feingold, G.: Modeling Mesoscale Cellular Structures and Drizzle in Marine Stratocumulus. Part I: Impact of Drizzle on the Formation and Evolution of Open Cells., J. Atmos. Sci., 66, 3237-3256, 2009a.

Wang, H. and Feingold, G.: Modeling Mesoscale Cellular Structures and Drizzle in Marine Stratocumulus. Part I: Impact of Drizzle on the Formation and Evolution of Open Cells., J. Atmos. Sci., 66, 3237-3256, 2009b.

Wang, H., Feingold, G., Wood, R., and Kazil, J.: Modelling microphysical and meteorological controls on precipitation and cloud cellular structures in Southeast Pacific stratocumulus, Atmos. Chem. Phys., 10, 6347-6362, doi:10.5194/acp-10-6347-2010, 2010.

Wang, S., O’Neill, L. W., Jiang, Q., de Szoeke, S. P., Hong, X., Jin, H., Thompson, W. T., and Zheng, X.: A regional real-time forecast of marine boundary layers during VOCALS-REx, Atmos. Chem. Phys., 11, 421-437, doi:10.5194/acp-11-421-2011, 2011.

Webb, E. K.: Profile relationships: The log-linear range, and extension to strong stability, Quart. J. Roy. Meteor. Soc., 96, 67-90, 1970.

Wood, R., Comstock, K. K., Bretherton, C. S., Cornish, C., Tomlinson, J., Collins, D. R., and Fairall, C.: Open cellular structure in marine stratocumulus sheets, J. Geophys. Res., 113, D12207, doi:10.1029/2007JD009,371, 2008.

Wood, R., Bretherton, C. S., Leon, D., Clarke, A. D., Zuidema, P., Allen, G., and Coe, H.: An aircraft case study of the spatial transition from closed to open mesoscale cellular convection over the Southeast Pacific, Atmos. Chem. Phys., 11, 2341-2370, doi:10.5194/acp-11-2341-2011, 2011.
Wood, R., Mechoso, C. R., Bretherton, C. S., Weller, R. A., Huebert, B., Straneo, F., Albrecht, B. A., Coe, H., Allen, G., Vaughan, G., Daum, P., Fairall, C., Chand, D., Gallardo Klenner, L., Garreaud, R., Grados, C., Covert, D. S., Bates, T. S., Krejci, R., Russell, L. M., de Szoeke, S., Brewer, A., Yuter, S. E., Springston, S. R., Chaigneau, A., Toniazzo, T., Minnis, P., Palikonda, R., Abel, S. J., Brown, W. O. J., Williams, S., Fochesatto, J., Brioude, J., and Bower, K. N.: The VAMOS Ocean-Cloud-Atmosphere-Land Study Regional Experiment (VOCALS-REx): goals, platforms, and field operations, Atmos. Chem. Phys., 11, 627-654, doi:10.5194/acp-11-6272011, 2011.

Wyant, M. C., Wood, R., Bretherton, C. S., Mechoso, C. R., Bacmeister, J., Balmaseda, M. A., Barrett, B., Codron, F., Earnshaw, P., Fast, J., Hannay, C., Kaiser, J. W., Kitagawa, H., Klein, S. A., Köhler, M., Manganello, J., Pan, H.-L., Sun, F., Wang, S., and Wang, Y.: The PreVOCA experiment: modeling the lower troposphere in the Southeast Pacific, Atmos. Chem. Phys., 10, 4757-4774, doi:10.5194/acp-10-4757-2010, 2010.

Yang, Q., W. I. Gustafson Jr., Fast, J. D., Wang, H., Easter, R. C., Morrison, H., Lee, Y.-N., Chapman, E. G., Spak, S. N., and Mena-Carrasco, M. A.: Assessing regional scale predictions of aerosols, marine stratocumulus, and their interactions during VOCALS-REx using WRF-Chem, Atmos. Chem. Phys., 11, 11951-11975, doi:10.5194/acp-11-11951-2011, 2011.

Zhang, D.-L. and Anthes, R.: A high-resolution model of the planetary boundary layer- sensitivity tests and comparisons with SESAME-79 data, J. Appl. Meteorol., 21, 1594-1609, 1982. 